Supplement of Solid Earth, 10, 59-78, 2019 https://doi.org/10.5194/se-10-59-2019-supplement (c) Author(s) 2019. This work is distributed under the Creative Commons Attribution 4.0 License.

(c) (1)

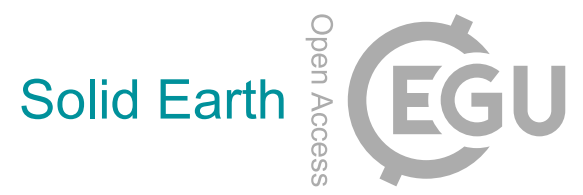

Supplement of

\title{
A multi-technology analysis of the 2017 North Korean nuclear test
}

Peter Gaebler et al.

Correspondence to: Peter Gaebler (peter.gaebler@bgr.de)

The copyright of individual parts of the supplement might differ from the CC BY 4.0 License. 


\section{Seismo-acoustic waves emitted from the underground nuclear test on September 3rd 2017 in North Korea}

Here we further discuss the acoustic signals observed at infrasound station IS45 arriving 12 and 16.5 minutes after the underground nuclear test origin time, as well as a signal family arriving 33.5 minutes after the origin time. All signal families have backazimuth values within $\pm 12^{\circ}$ of the test site backazimuth direction $\left(218^{\circ}\right)$ and show acoustic trace velocities indicative of arriving infrasonic waves. But if these signatures originate at the epicenter location and during the nuclear test origin time, the first two signal families would result in celerities beyond $550 \mathrm{~m} / \mathrm{s}$ and beyond $400 \mathrm{~m} / \mathrm{s}$ and the third one in celerities below $200 \mathrm{~m} / \mathrm{s}$. All these celerity values are outside the typical ranges of ducted infrasound (between around $240 \mathrm{~m} / \mathrm{s}$ and $350 \mathrm{~m} / \mathrm{s}$ ). Frequency-wavenumber (FK) and Progressive Multi-Channel Correlation (PMCC, Cansi, 1995) analysis results for these precursory and late arrivals are shown in Figure 1. Waveform data starts at 03:30 UTC, i.e. near the event's origin time, and shows, beyond the epicentral infrasound between 1200 and $1700 \mathrm{~s}$ (as described in Figure 11 in the main text) also the seismic phases within the first $200 \mathrm{~s}$ and after $700 \mathrm{~s}$, a subtle increase in waveform amplitudes, constituting the aforementioned precursory signals. After a total of $2000 \mathrm{~s}$, a late arrival as described above is also shown.

When these precursory signals are scrutinized by FK and PMCC analysis, acoustic signal properties are found, i.e. slowness values of $320 \mathrm{~s} / \mathrm{deg}$ resembling about $350 \mathrm{~m} / \mathrm{s}$ trace velocity. While the first arrival's backazimuth of $206.0^{\circ}$ (FK) or $207.4^{\circ}$ (PMCC) is more than 10 degrees from the great circle path direction towards the test site, the second signal is closer thereto with a backazimuth of $218.9^{\circ}$ (FK) or $222.4^{\circ}$ (PMCC). The late arrival originates from a direction estimated to be $216.9^{\circ}$ (FK) or $218.2^{\circ}$ (PMCC). To explain the precursory signals, we assume the conversion of a seismic wave originating from the nuclear test to an acoustic wave at certain terrain features (Le Pichon et al., 2006; Walker et al., 2013). We apply a similar technique for backprojection as used by Shani-Kadmiel et al. (2018) and combine the initial seismic wave, a crustal P phase with propagation velocities of $6 \mathrm{~km} / \mathrm{s}$ with an infrasonic wave having average acoustic celerities of $280 \mathrm{~m} / \mathrm{s}$ (as found for the epicentral arrivals). This results in the most likely seismo-acoustic conversion area for the initial precursory arrival being in the border region of North Korea, China and Russia, southeast of the great circle path between test site and receiver. The conversion region of the second precursor is then a region within North Korea, but further to the south-west and just north of the great circle path (Figure 2, left). These results correlate well with the studies by Pilger and Koch (2018) and Assink et al. (2018).

Backtracking the epicentral infrasound arrivals (as shown in Figure 11 in the main text) we obtain a large area around the test site extending either to the northeast or the southwest as an expression of the two major signal groups corresponding to the stratospheric and thermospheric arrivals (Figure 2, right). Assuming that the precursory signals are from stratospheric ducting and the celerity values are underestimated, i.e. the patch to the northeast of the epicenter is an expression thereof, the actual conversion regions of the precursor arrivals may be biased towards the northeast, and in reality could be slightly further to the

\section{0 southwest.}

To explain the late signal arrival about eight minutes after the epicentral infrasound, we assume acoustic wave propagation directly from the test site by the aftershock and cavity collapse eight minutes after the nuclear test. This is supported by the observed infrasonic backazimuth directions, velocities and travel times, as well as by the implosive (collapsing) characteristic of the aftershock derived from moment tensor decomposition and the indications of large surface movements by satellite remote sensing within this manuscript. 


\section{References}

Assink, J., Averbuch, G., Shani-Kadmiel, S., Smets, P., and Evers, L.: A Seismo-Acoustic Analysis of the 2017 North Korean Nuclear Test, Seismological Research Letters, https://doi.org/10.1785/0220180137, 2018.

Cansi, Y.: An automatic seismic event processing for detection and location: The P.M.C.C. Method, Geophysical Research Letters, 22, 1021-1024, https://doi.org/10.1029/95GL00468, 1995.

Le Pichon, A., Mialle, P., Guilbert, J., and Vergoz, J.: Multistation infrasonic observations of the Chilean earthquake of 2005 June 13 , Geophysical Journal International, 167, 838-844, 2006.

Pilger, C. and Koch, K.: Infrasound from the 2017 DPRK underground nuclear test, in: EGU General Assembly Conference Abstracts, vol. 20 of EGU General Assembly Conference Abstracts, p. 7827, 2018.

10 Shani-Kadmiel, S., Assink, J. D., Smets, P. S. M., and Evers, L. G.: Seismoacoustic Coupled Signals From Earthquakes in Central Italy: Epicentral and Secondary Sources of Infrasound, Geophysical Research Letters, 45, 427-435, https://doi.org/10.1002/2017GL076125, 2018.

Walker, K. T., Pichon, A. L., Kim, T. S., Groot-Hedlin, C., Che, I.-Y., and Garcés, M.: An analysis of ground shaking and transmission loss from infrasound generated by the 2011 Tohoku earthquake, Journal of Geophysical Research: Atmospheres, 118, 12,831-12,851, 2013. 


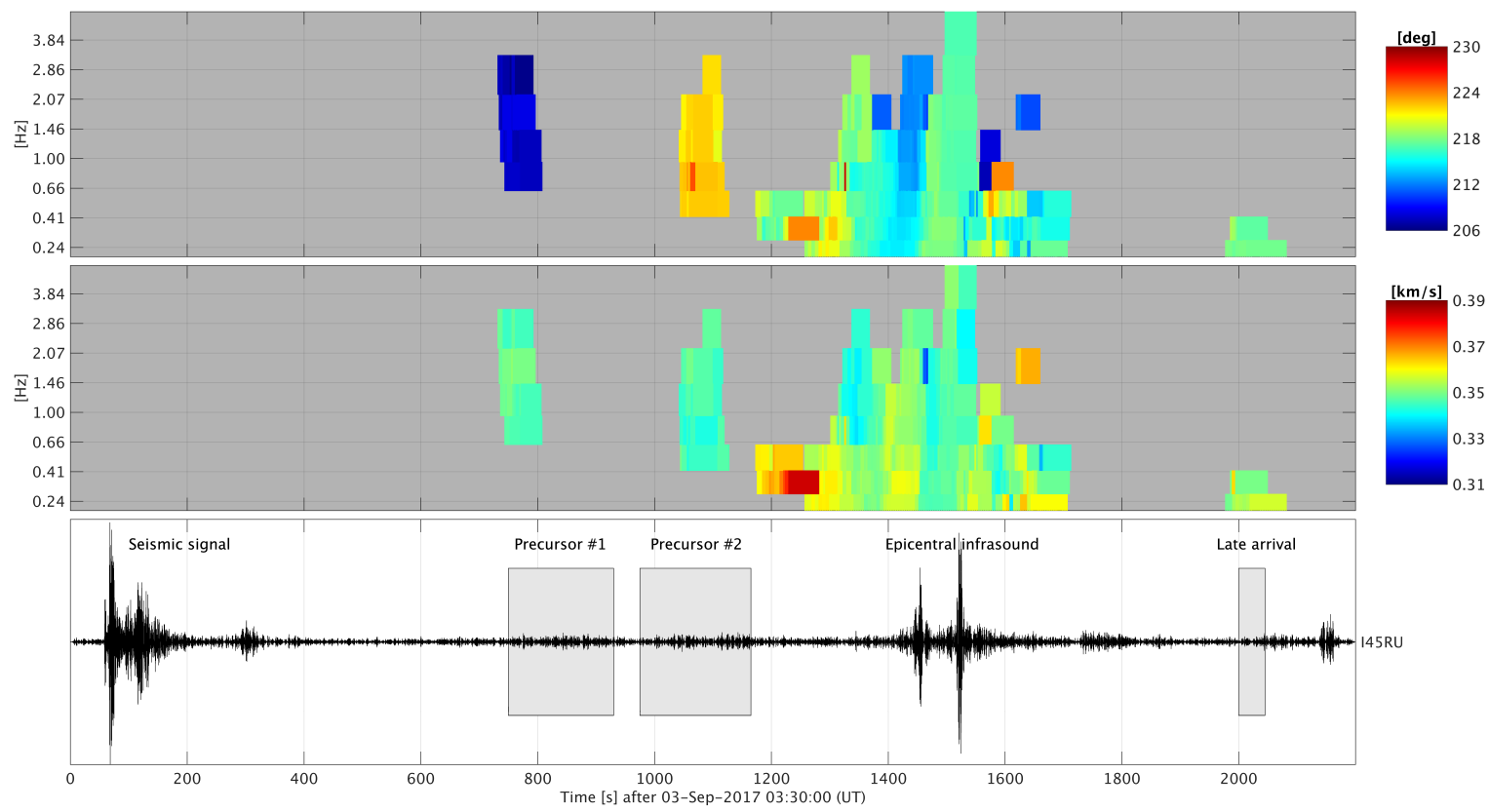

(a) Top: PMCC analysis. Bottom: waveforms associated to the test.
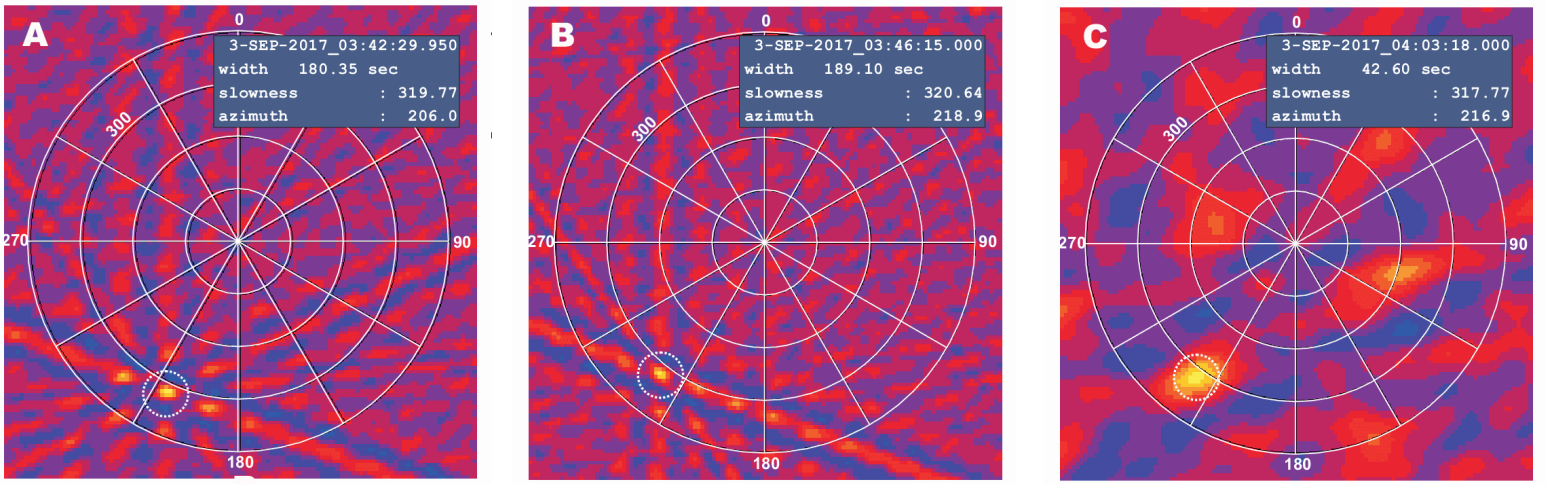

(b) Frequency-wavenumber analysis for the two precursors and the late arrival.

Figure 1. (a, top) PMCC analysis results are shown on the top with acoustic signal detections for the precursory arrivals as well as the later arrival and confirm the results from FK-analyses. (a, bottom) Waveforms for a 35 minute time window starting at the origin time of the underground explosion, displaying seismic waves near the beginning and also the strong infrasound signals shown in Fig. 11. (b) Results of FK analyses of additional signal windows are shown on the bottom, with (A) for precursor 1 and (B) for precursor 2 . Some weak signal near the end of the record, labeled late arrival, produces the FK result $(\mathrm{C})$, indicating again acoustic arrival properties. 

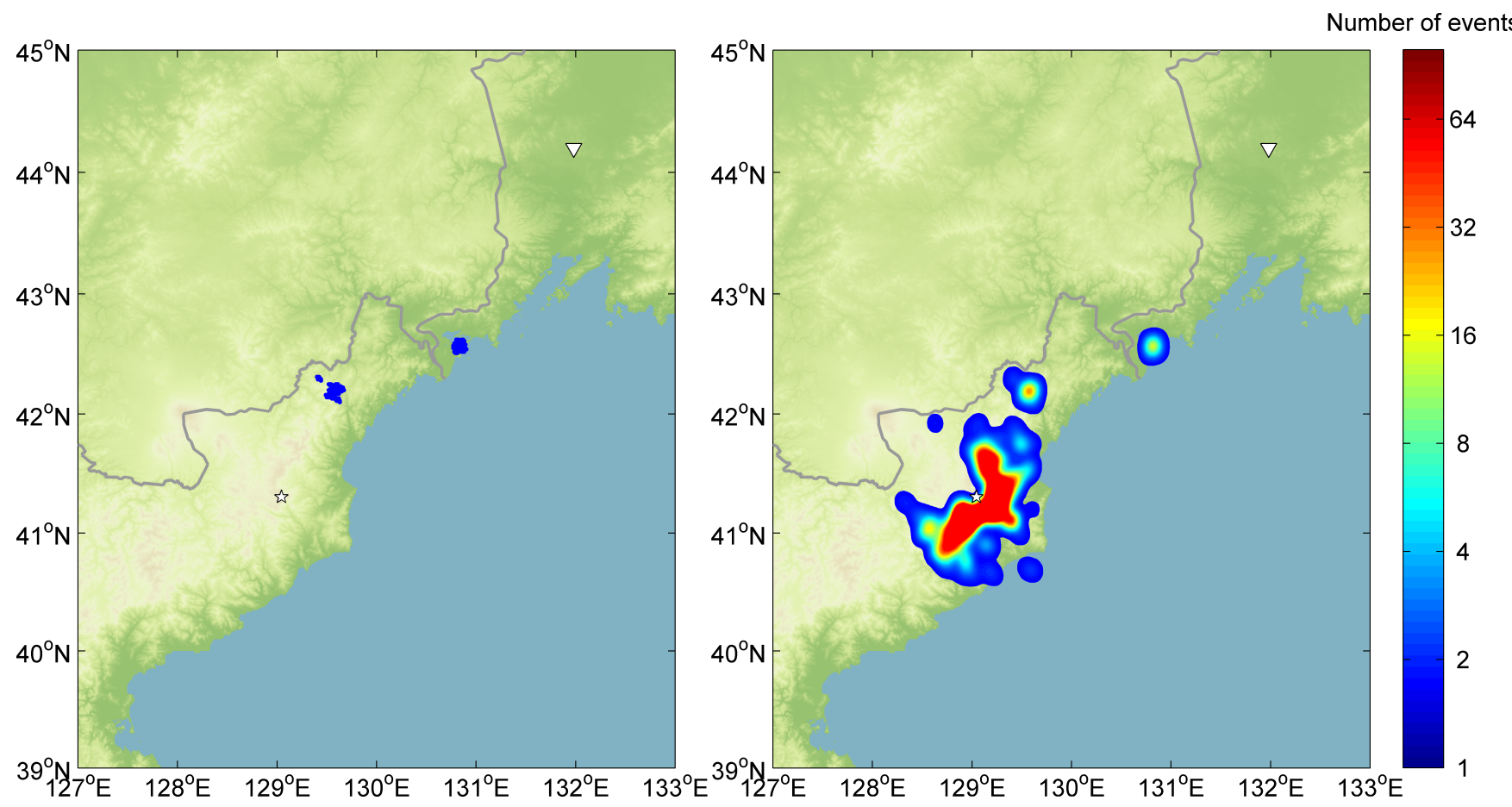

Figure 2. Backtracking of the acoustic waveform energy using the PMCC detection pixels shown in Fig. 1 with identification of the seismicacoustic conversion regions for an initial crustal $\mathrm{P}$ wave path. The grid used extends from 40 to $44^{\circ} \mathrm{N}$ and 128 to $132^{\circ} \mathrm{E}$ with a grid interval of $0.01^{\circ}$ in either direction. (left) Results of backtracking using only the acoustic energy preceding the epicentral infrasound arrivals with corresponding grid points. (right) Conversion regions for all infrasound arrivals including the epicentral signals from contouring the spatial frequency distribution (see colorbar). 